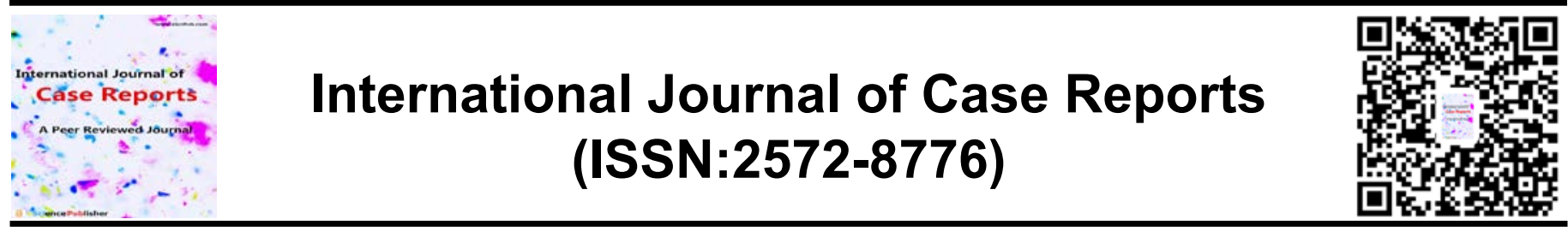

\title{
Late Presentation of Posterior Urethral Valve in a 24-Year-old Man
}

\section{OO Moemenam ${ }^{1}$, NR Njeze $^{2}$ and OD Ray-Offor ${ }^{3}$}

${ }^{1}$ Department of Radiology, Federal Medical Centre, Owerri, Imo State, Nigeria;

${ }^{2}$ Department of Radiation Medicine, University of Nigeria Teaching Hospital, ItukuOzalla, Enugu State, Nigeria;

${ }^{3}$ Department of Radiology, University of Port Harcourt Teaching Hospital, Port Harcourt, Rivers State, Nigeria.

\section{INTRODUCTION}

Posterior urethral valve (PUV) is the most common cause of lower urinary tract obstruction in male neonates, with an incidence of one case per 8,000 to 25,000 live births 1 . The diagnosis is usually made prenatally or at birth, when male newborns are evaluated for prenatal hydronephrosis, or during early childhood, but rarely during adolescence or adulthood. Late presentation of PUV is rare and it has been estimated to account for $10 \%$ of cases2. Presentation in adulthood may occur due to the presence of a mild form of the disease devoid of the life threatening complications seen in children with the severe form3.

A rare case of PUV which manifested in adulthood with lower urinary symptoms is presented to create awareness of the likelihood of the disease outside the paediatric age group.

\section{How to cite this article:}

OO Moemenam, NR Njeze and OD Ray-Offor. Late Presentation of Posterior Urethral Valve in a 24 -Year-old Man. International Journal of Case Reports, 2019 4:67

Conflict of interest: None
*Correspondence to Author:

OO Moemenam

Department of Radiology, Federal Medical Centre, Owerri, Imo State, Nigeria

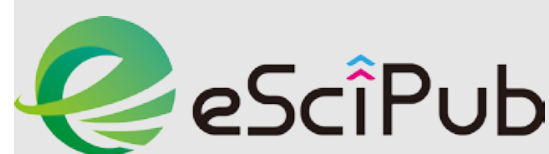
eSciPub LLC, Houston, TX USA. Website: http://escipub.com/ 


\section{CASE REPORT}

$\mathrm{O}$. J. is a 24-year-old student who presented to the Urology Clinic of Federal Medical Centre, Owerri, with history of increased frequency in urination of 10 weeks duration. The symptom was said to have started gradually and progressively worsened over time. There was good streaming of urine, even though he felt the quantity increased because he spent more time passing out urine. There was associated dribbling, urge incontinence, hesitancy and feeling of incomplete emptying of bladder. There was also early morning swelling of the feet up to the ankle, noticed mainly in the right, and relieved when he walked around for a while. No associated facial puffiness, fever, pain on micturition, lumbar pain or urethral discharge. For these symptoms, he had been treated with antibiotics which were prescribed at a medical laboratory, but without any improvement. He then decided to come to our hospital for expert management.

Past medical history revealed that he was diagnosed and treated for syphilis about 3 years ago at a peripheral hospital. He also had dysuria about 7 months prior to presentation, which he treated using herbal medications. Family and social history was not significant.

Physical examination revealed a young man, not pale, anicteric, afebrile, acyanosed, mildly dehydrated with no pedal oedema.

Abdominal examination revealed a mass in the suprapubic region which was 20 weeks in size, well defined, rounded and firm. Chest and cardiovascular system examinations were not contributory. Urinalysis showed pus cells (+), while urine culture did not yield any growth of organisms. Serum electrolytes, urea and creatinine values obtained were deranged: urea $131 \mathrm{mg} / \mathrm{dl}$ (normal range $=15-40$ ), creatinine $2.6 \mathrm{mg} / \mathrm{dl}(0.5-1.5), \mathrm{K}^{+} 6.7 \mathrm{mmol} / \mathrm{l}(3.5-5)$ and $\mathrm{Cl}^{-} 111 \mathrm{mmol} / \mathrm{l}$ (96 - 108). Abdominal ultrasound (US) scan revealed moderate bilateral hydronephrosis. The urinary bladder was markedly dilated with thickened wall. A diverticulum was noted on the right side of the urinary bladder. Provisional diagnosis of urinary bladder outlet obstruction? secondary to urethral stricture was made. $\mathrm{He}$ was catheterized and sent for micturatingcystourethrogram (MCUG) and retrograde urethrocystogram (RUCG).

The RUCG showed the anterior urethra that is normal in calibre and outline (Fig.1). The MCUG showed a grossly dilated posterior urethra. The bladder wall was thickened and had trabeculations with a contrast filled outpouching on the right (diverticulum) (Fig.2). There was no vesicoureteric reflux. He was then booked for urethrocystoscopy and resection of posterior urethral valve.

During the urethrocystoscopy, a posterior urethral valve was noted just after the bladder neck and internal sphincter. The posterior urethral valve was avulsed as the beak of the urethrocystoscope was advanced into the urinary bladder. He was placed on antibiotics and catheterized in order to maintain continuous bladder drainage for one week post op.

$\mathrm{He}$ is currently being jointly managed with the nephrology unit for chronic renal failure. On follow up, he has remained well with resolution of his symptoms as well as improvement in his deranged electrolytes, urea and creatinine.

\section{DISCUSSION}

Posterior urethral valve (PUV) is a congenital malformation found in males that is characterized by the presence of abnormal obstructing membranes in the posterior urethra. The exact embryology of the condition is not completely understood but it is believed to arise mainly as a result of an anomalous insertion of the mesonephric duct into the primitive fetal cloaca 4 . This leads to an obstruction in the flow of urine through the urethra with the classic presentation of poor stream at birth. It is the most common cause of bladder outlet obstruction in male children and can be complicated by urinary tract infection (UTI), 
structural changes in the urinary tract and impaired renal function ${ }^{5}$.In cases with mild obstruction, presentation may be delayed until later in life.

Young et $\mathrm{al}^{2}$ classified PUV into three types.

- $\quad$ Type 1 - mucosal folds extend distally from each side of the verumontanum towards the membranous urethra where they fuse anteriorly.

- $\quad$ Type 2 -mucosal folds extend cephalad from the verumontanum to the bladder neck.

- $\quad$ Type 3 - represents a diaphragm or ringlike membrane with a central aperture just distal to the verumontanum ${ }^{6}$.

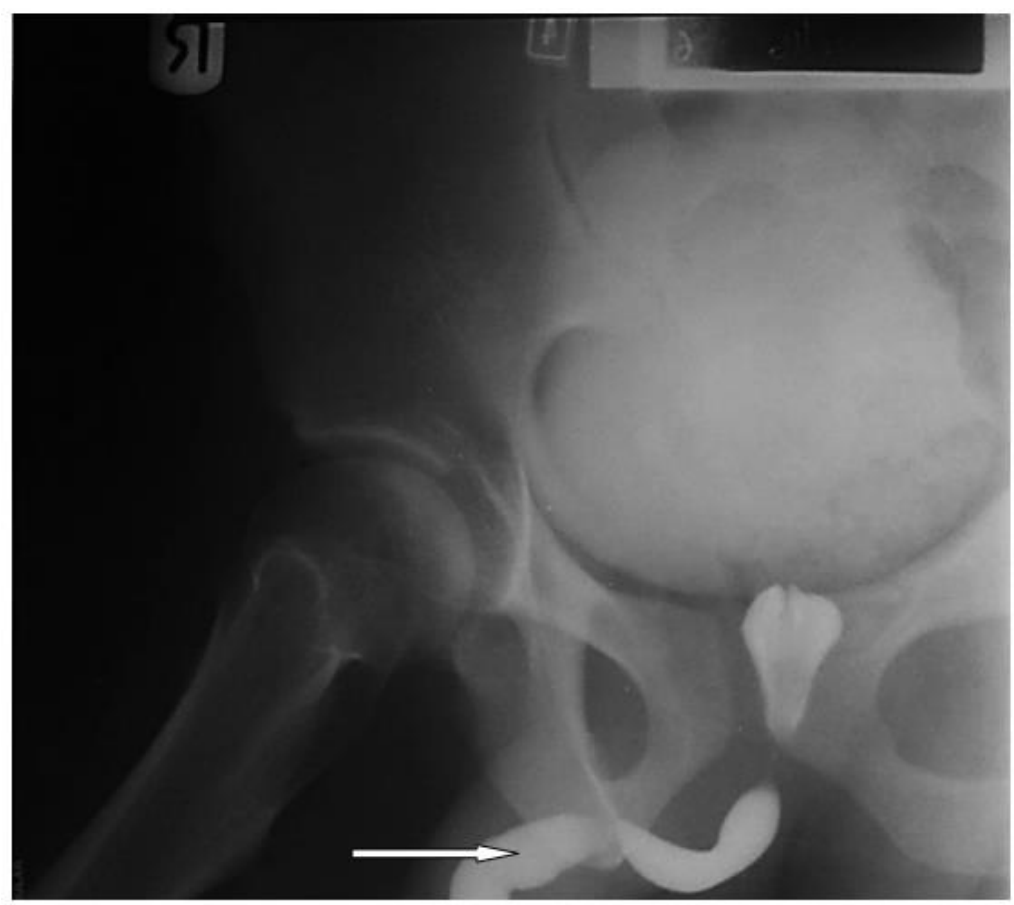

Fig.1. RUCG showing the normal anterior urethra (white arrow). The posterior urethra is mildly dilated.

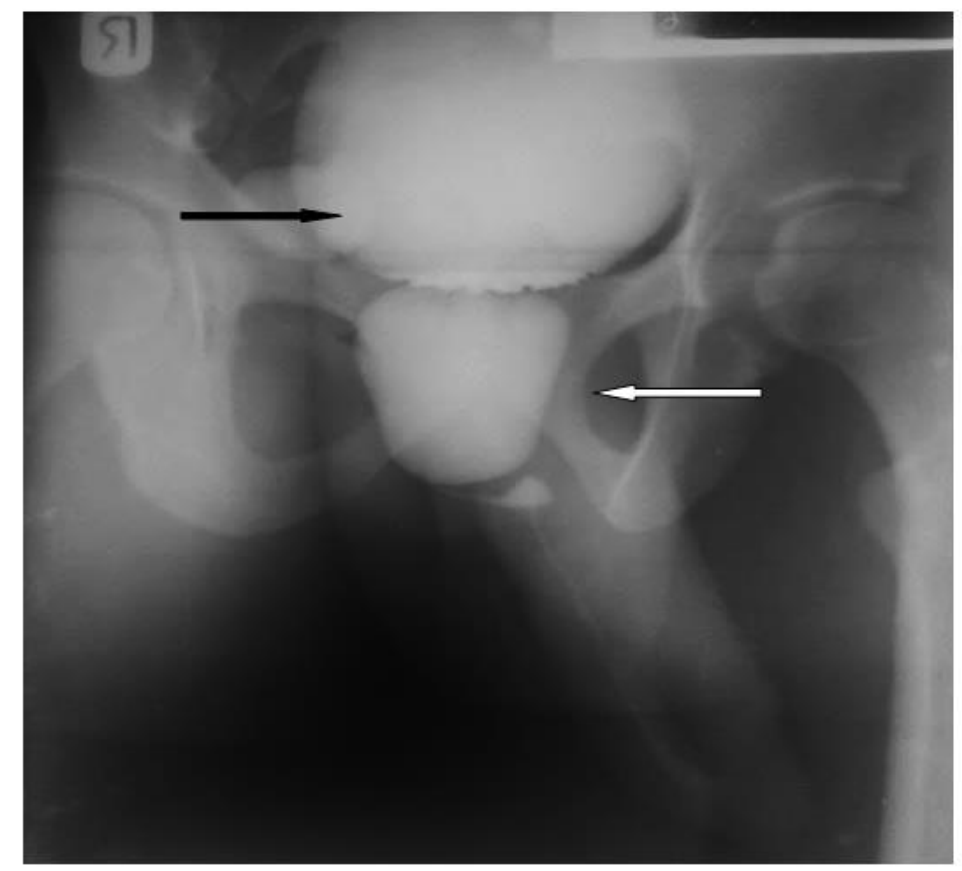

Fig.2. MCUG showing the markedly dilated posterior urethra (white arrow) and the urinary bladder diverticulum (black arrow). The urinary bladder is also thick-walled and trabeculated. 
The incidence of PUV in Nigeria is not known. However PUV together with other congenital obstructive uropathy accounted for $1.4-6.4 \%$ of all renal diseases in most of the centres in Nigeria $^{6,7}$. No racial, ethnic or geographical predilection is noted.

The usual presentation of PUV is prenatal or at birth. The symptoms and signs of late presentation of PUV depend mainly on the degree of obstruction and the presence of complications. The most common presentations include poor or weak urine stream, dribbling at voiding, urinary frequency, feeling of incomplete urinary bladder emptying and urge incontinence, as in the index case. Patient may also present with repeated urinary tract infection and chronic renal failure, which are common clinical features in adolescents and adults. Other rare situations that could be related to late presentation of PUV may include retained ejaculation and infertility. Agbuguiet $\mathrm{al}^{3}$ reported an unusual case of primary male infertility in an adult with PUV in Benin Nigeria.

Imaging is frequently employed in the confirmation of diagnosis of PUV. Ultrasonography may show hydronephrosis, with or without cortical thinning. Hydroureters and thick-walled bladder with trabeculation and diverticula may also be seen. In younger patients, a dilated posterior urethra with a hypertrophic bladder neck may be noted. This feature was not demonstrated in the index patient, on ultrasound. Echogenic lines that are the actual valve leaflets might be seen. The combination of the dilated, thick-walled bladder and dilated posterior urethra has been described as having a keyhole appearance. MCUG is considered the diagnostic study of choice for the evaluation of posterior urethral valves $^{8}$. The diagnosis is best made during the micturition phase in a lateral or oblique view, such that the posterior urethra can be imaged adequately. Findings may include dilatation and elongation of the posterior urethra, vesicoureteric reflux (VUR), bladder trabeculation or diverticular. Linear radiolucent band corresponding to the valve may occasionally be seen. In the present patient, ultrasonography showed the bilateral hydronephrosis, while the MCUG was able to clearly demonstrate the dilated posterior urethra. Intravenous urography (IVU) is not routinely used in the diagnosis of PUV, but may show hydroureteronephrosis when present. Delayed images may show bladder pathology, but the lower urinary tract is better visualized with MCUG. Computed tomography (CT) and magnetic resonance imaging (MRI) are rarely necessary because they cannot reliably depict valves, although they may reveal the sequelae of bladder outlet obstruction.

Generally, treatment of PUV involves transurethral ablation of the valve. Electrosurgical fulguration with a Bugbee electrode through aurethrocystoscope is the commonest treatment option for management of PUV ${ }^{9}$. The valves may also be incised with a cold knife. In this patient, the valve was avulsed using the beak of the urethrocystoscope which gave a satisfactory result. Late presentation of PUV could be a cause of chronic renal failure whether or not it has been treated. Parkhouseet al $^{10}$ reported on long-term follow-up among treated postpubertal patients and showed that $26 \%$ of them had chronic or end-stage renal failure. The index patient is currently being managed for chronic renal failure

\section{SUMMARY}

A rare case of posterior urethral valve in a 24year-old man has been presented. The varying clinical presentation, diagnostic modalities and treatment options have also been discussed. This case highlights the need to remain alert to the possibility of late diagnosis of PUV.

Conflict of interest: None

\section{REFERENCES}

1. Atwell JD. Posterior urethral valves in the British Isles: a multicentre B.A.P.S review. J Paediatr Surg. 1983; 18:70-4.

2. Young $\mathrm{HH}$, Frontz WA, Baldwin JC. Congenital obstruction of the posterior urethra. J Urol. 2002; 167:265-7. 
3. Agbugui JO, Omokhudu O. Posterior urethral valve: an unusual cause of primary male infertility. J Reprodlnfertil. 2015; 16:113-5.

4. Krishnan A, de Souza A, Konijeti R, Baskin LS. The anatomy and embryology of posterior urethral valves. J Urol. 2006; 175:1214-20.

5. Warren J, Pike JG, Leonard MP. Posterior urethral valves in Eastern Ontario - a 30 year perspective. Can J Urol. 2004; 11:2210-5.

6. Eke FU, Eke NN. Renal disorders in children: a Nigerian study. PaediatrNephrol. 1994; 8:3836.

7. Okoro BA, Okafor HU. Pattern of childhood renal disorder in Enugu Nigeria. Niger $\mathrm{J}$ Paediatr. 1999; 26:14-18.

8. Gupta RK, Shah HS, Jadhav V. Urethral ratio on voiding cystourethrogram: a comparative method to assess success of posterior urethral valve ablation. J Paediatr Urol. 2010; 6:32-6.

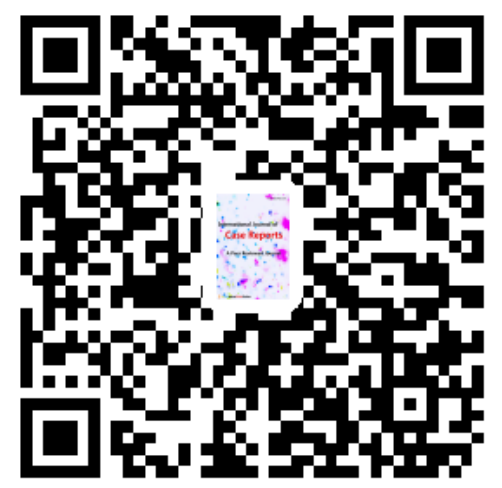

9. Martin J, Anderson J, Raz S. Posterior urethral valves in adults: a report of 2 cases. J Urol. 1977; 118:978-9.

10. Parkhouse HF, Barrat TM, Dillon MJ, Duffy PG, Fay J, Ransley PG, et al. Long-term outcome of boys with posterior urethral valves. $\mathrm{Br} \mathrm{J}$ Urol. 1988; 62:59-62. 